\title{
The Importance of Flexion MRI in Hirayama Disease with Special Reference to Laminodural Space Measurements
}

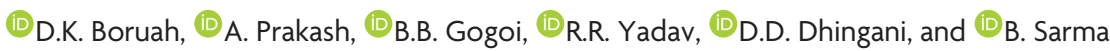

\begin{abstract}
BACKGROUND AND PURPOSE: Hirayama disease is a benign focal amyotrophy of the distal upper limbs involving C7, C8, and T1 segmental myotomes with sparing of the brachioradialis and proximal muscles of the upper limb innervated by $\mathrm{C} 5-6$ myotomes. The objective of the present study was to study the utility of MR imaging in young patients presenting with weakness and wasting of the distal upper extremity and to evaluate the importance of the laminodural space during flexion cervical MR imaging.
\end{abstract}

MATERIALS AND METHODS: This was a prospective cross-sectional study conducted from January 2014 to July 2017 in a tertiary care center from Northeast India. Forty-five patients with clinically definite Hirayama disease underwent electrophysiologic evaluation followed by MR imaging of the cervical spine.

RESULTS: The mean age at recruitment was $22.8 \pm 5.5$ years. Forty patients $(88.9 \%)$ had unilateral and 5 (11.1\%) had bilateral upper extremity involvement. Cervical cord T2-weighted hyperintensities were demonstrated in 16 patients (35.6\%), of which 15 (33.3\%) had anterior horn cell hyperintensities. Flexion MR imaging showed loss of the posterior dural attachment, forward shifting of the posterior dural sac with postcontrast enhancement, and prominent posterior epidural venous plexus in all patients. The laminodural space at maximum forward shifting of the posterior dural sac ranged from 3 to $9.8 \mathrm{~mm}$, with a mean distance of $5.99 \mathrm{~mm}$ ( $95 \%$ confidence interval, $5.42-6.57 \mathrm{~mm}$ ).

CONCLUSIONS: Flexion cervical MR imaging is a very useful investigation in diagnosing Hirayama disease. The increase in the laminodural space and the presence of cervical cord flattening during flexion are essential for diagnosis.

ABBREVIATIONS: $A P=$ anteroposterior $; \mathrm{HD}=$ Hirayama disease $; \mathrm{LDS}=$ laminodural space; $\mathrm{TR}=$ transverse

$\mathrm{H}^{\mathrm{s}}$ irayama disease (HD) was initially described by Hirayama et $\mathrm{al}^{1}$ in 1959 in a Japanese patient with unilateral atrophy of the distal upper limb. It was later coined "juvenile muscular atrophy" of distal upper limb extremity ${ }^{2}$ or "monomelic amyotrophy." ${ }^{3} \mathrm{HD}$ is characterized by an insidious-onset asymmetric wasting with weakness of the distal muscles of the upper extremity, sparing of the brachioradialis (oblique amyotrophy), and predominant affect on the $\mathrm{C} 8-\mathrm{T} 1$ segmental myotomes. ${ }^{4}$ Very rarely, atypical HD may affect the lower limbs. ${ }^{5}$ The disease commonly affects young individuals in their second-to-third decades

Received September 10, 2017; accepted after revision December 30.

From the Departments of Radiodiagnosis (D.K.B., D.D.D.) and Neurology (B.S.), Assam Medical College and Hospital, Dibrugarh, Assam, India; Department of Radiodiagnosis (A.P.), Bangalore Medical College and Research Institute, Bangalore, Karnataka, India; Department of Pathology (B.B.G.), North Eastern Indira Gandhi Regional Institute of Health and Medical Sciences, Meghalaya, India; and Department of Radiodiagnosis (R.R.Y.), Sanjay Gandhi Postgraduate Institute of Medical Sciences, Lucknow, India.

Please address correspondence to Arjun Prakash, MD, Department of Radiodiagnosis, Bangalore Medical College and Research Institute, Fort, K.R. Road, Bangalore 560002, Karnataka, India; e-mail: drarjunprakash@gmail.com

http://dx.doi.org/10.3174/ajnr.A5577 of life with a predominant age of onset of around 15-25 years. ${ }^{6}$ Males are more affected than females. ${ }^{6}$ Initial oblique unilateral amyotrophy more frequently affects the right upper limb than the left, with subsequent contralateral upper limb affection in 50\% of cases. ${ }^{3,7}$ Bilateral symmetric or asymmetric involvement of HD was also reported. ${ }^{8}$ Lai et $\mathrm{al}^{9}$ noted that forward shifting of the posterior cervical dural sac can occur in healthy subjects also on flexion MR imaging (ranging from 1.0 to $4.2 \mathrm{~mm}$ compared with those with HD ranging from 6.1 to $7.8 \mathrm{~mm}$ ).

The aim of the study was to evaluate the utility of MR imaging in young patients presenting with distal upper extremity muscle wasting and weakness and to evaluate the importance of the laminodural space (LDS) during flexion cervical MR imaging.

\section{MATERIALS AND METHODS Patient Selection}

The study was approved by the institutional ethics review committee. Informed and written consent was obtained from all the participants. The study group comprised patients presenting to the departments of radiodiagnosis, neurology, neurosurgery, and medicine in a tertiary care center from January 2014 to July 2017. 
We included all young adults who presented to the outpatient department with weakness and wasting of the hand and/or forearm muscles with motor axonopathy in nerve-conduction studies. Patients with different etiologies with similar presentations were excluded from the study. Patients with an acute history of trauma, previous cervical spinal fixation or prosthesis, and those diagnosed with ankylosing spondylitis affecting the cervical spine were all excluded. Fifty-six patients with clinically suspected HD were recruited. We excluded 4 due to an inability to achieve adequate neck flexion (3 due to obesity and 1 due to ankylosing spondylitis). Seven patients were excluded due to excessive motion artifacts during flexion MR imaging.

Forty-five patients composed the final study group. Motor and sensory nerve conduction studies were performed under standard guidelines. The conduction velocities and compound muscle action potential amplitudes of the median and ulnar nerves were measured for analysis.

\section{MR Imaging Protocol}

MR imaging was performed using a 1.5T Magnetom Avanto B15 machine (Siemens, Erlangen, Germany). Image acquisition of the cervical spine was initially performed with patients in a supine neutral position in routine sagittal T2- and T1-weighted spinecho, sagittal and coronal STIR, and axial T2- and T1-weighted fast spin-echo and axial 2D T2*WI gradient recalled-echo sequences. Sagittal spin-echo T1WI was acquired with a TR/TE of 450-500/9-15 ms; sagittal T2WI, with a TR/TE of 4000-4600/ $110-120 \mathrm{~ms}$ with a $3-\mathrm{mm}$ slice thickness. Axial 2D T2* WI gradient recalled-echo imaging was performed with a TR/TE of 650$750 / 24-32 \mathrm{~ms}$ and a flip angle of $24^{\circ}-28^{\circ}$.

Flexion MR imaging of the cervical spine was performed with a body coil without using a cervical coil. The optimum neck flexion of $30^{\circ}-40^{\circ}$ was obtained after putting soft MR imaging-compatible support behind the nape of neck with further support on either side of the neck to create immobility of the neck during flexion MR imaging. Postgadolinium fat-suppressed sagittal and axial T1-weighted images of the cervical spine were obtained in neck flexion with a slice thickness of $3 \mathrm{~mm}$.

\section{Image Analysis}

MR images were analyzed for cord flattening, cord atrophy, and T2weighted hyperintensities in the cord or in the region of the anterior horn cells. The maximum forward shifting of the posterior dural sac or LDS was measured in midline on postgadolinium fat-suppressed sagittal T1-weighted imaging on flexion MR imaging.

The LDS was measured at the maximum thickness of the dural detachment and enhancing posterior epidural component on postcontrast images. We also obtained the anteroposterior (AP) and transverse (TR) diameters of the cervical cord in axial images both in neutral and flexion MR imaging at the site of maximum forward shifting of the posterior dural sac. The spinal canal diameters were measured both in neutral and flexion sagittal MR images. The AP cervical spinal canal diameter on flexion MR imaging was measured at the site of maximum forward dural shift. The LDS and AP and TR diameters of the cervical cord during neutral and flexion MR imaging were measured in precontrast images and were compared with postgadolinium fat-suppressed images
Table 1: Anteroposterior spinal cord diameters in 45 patients with HD

\begin{tabular}{cccc}
\hline Vertebral Levels & $\begin{array}{c}\text { Minimum Cord } \\
\text { Diameter }(\mathbf{m m})\end{array}$ & $\begin{array}{c}\text { Maximum Cord } \\
\text { Diameter }(\mathbf{m m})\end{array}$ & Mean \\
\hline C2 & 6.27 & 8.11 & $7.13 \pm 0.43$ \\
C3 & 5.56 & 7.84 & $6.91 \pm 0.63$ \\
C4 & 4.99 & 7.54 & $6.50 \pm 0.62$ \\
C5 & 4.58 & 7.60 & $6.06 \pm 0.71$ \\
C6 & 3.97 & 6.98 & $5.64 \pm 0.73$ \\
C7 & 4.15 & 6.91 & $5.61 \pm 0.71$ \\
T1 & 4.75 & 7.73 & $5.93 \pm 0.56$ \\
\hline
\end{tabular}

by 2 radiologists. The average value obtained from the 2 authors was compared for any variability using the $F$ test and Pearson correlation. Other MR imaging findings such as cord atrophy and T2-weighted cord hyperintensities were observed by only 1 radiologist. The anteroposterior spinal cord diameters were measured at the midsagittal section from the $\mathrm{C} 2$ to $\mathrm{T} 1$ vertebral levels. The cord diameter was measured at the midvertebral level of each vertebra.

\section{Statistical Analysis}

Data were presented as percentage, mean, and SD. Calculations were performed with SPSS programs (IBM, Armonk, New York).

\section{RESULTS}

Forty-five patients comprised 44 (97.8\%) males and 1 (2.2\%) female. The age of presentation varied from 14 to 42 years, with a mean age of $22.8 \pm 5.5$ years. The duration of illness was $>2$ years in 30 patients $(66.7 \%)$ and $<2$ years in 15 patients $(33.3 \%)$. Forty patients $(88.9 \%)$ had an affected unilateral upper extremity while 5 patients $(11.1 \%)$ had bilateral involvement. All 45 patients $(100 \%)$ had weakness and wasting of the affected hand muscles, 27 patients $(60 \%)$ had wasting of forearm muscles, and 2 patients (4.4\%) had weakness of arm muscles. Thirty patients $(66.7 \%)$ had cold paresis in the affected hand, 22 patients (48.9\%) had hyperaesthesia in the hand, and 23 patients $(51.1 \%)$ had fasciculations in the affected muscles.

Neutral-position cervical MR imaging showed loss of cervical lordosis in 39 patients $(86.7 \%)$ and localized lower cervical cord atrophy in 27 patients $(60 \%)$. The cord atrophy was $<2$ vertebral heights in 19 patients (42.2\%), 2-3 vertebral heights in 5 patients $(11.1 \%)$, and $>3$ vertebral heights in 3 patients $(6.7 \%)$. The maximum cord atrophy was observed at the C6 and C7 vertebral levels (Table 1). Asymmetric cervical cord flattening was noted in 31 patients (68.9\%) (Figs 1 and 2). Intramedullary cervical cord T2weighted hyperintensities were noted in 16 patients (35.6\%), of whom 8 patients $(17.8 \%)$ had an involvement of $<2$ vertebral heights, 6 patients $(13.3 \%)$ had involvement of $2-3$ vertebral heights (Fig 3), and 2 patients (4.4\%) had an involvement of $>3$ vertebral heights. T2-weighted hyperintensities involving the anterior horn cells were noted in 15 patients $(33.3 \%)$, of whom 11 patients $(24.4 \%)$ had unilateral affection of the anterior horn cells and 4 patients $(8.9 \%)$ had bilateral affection. Flexion cervical MR imaging showed loss of the dural attachment, forward shifting of the posterior dural sac, and a postgadolinium fat-suppressed enhancing prominent posterior epidural space in all 45 patients (100\%) with HD (Figs 1 and 2). 

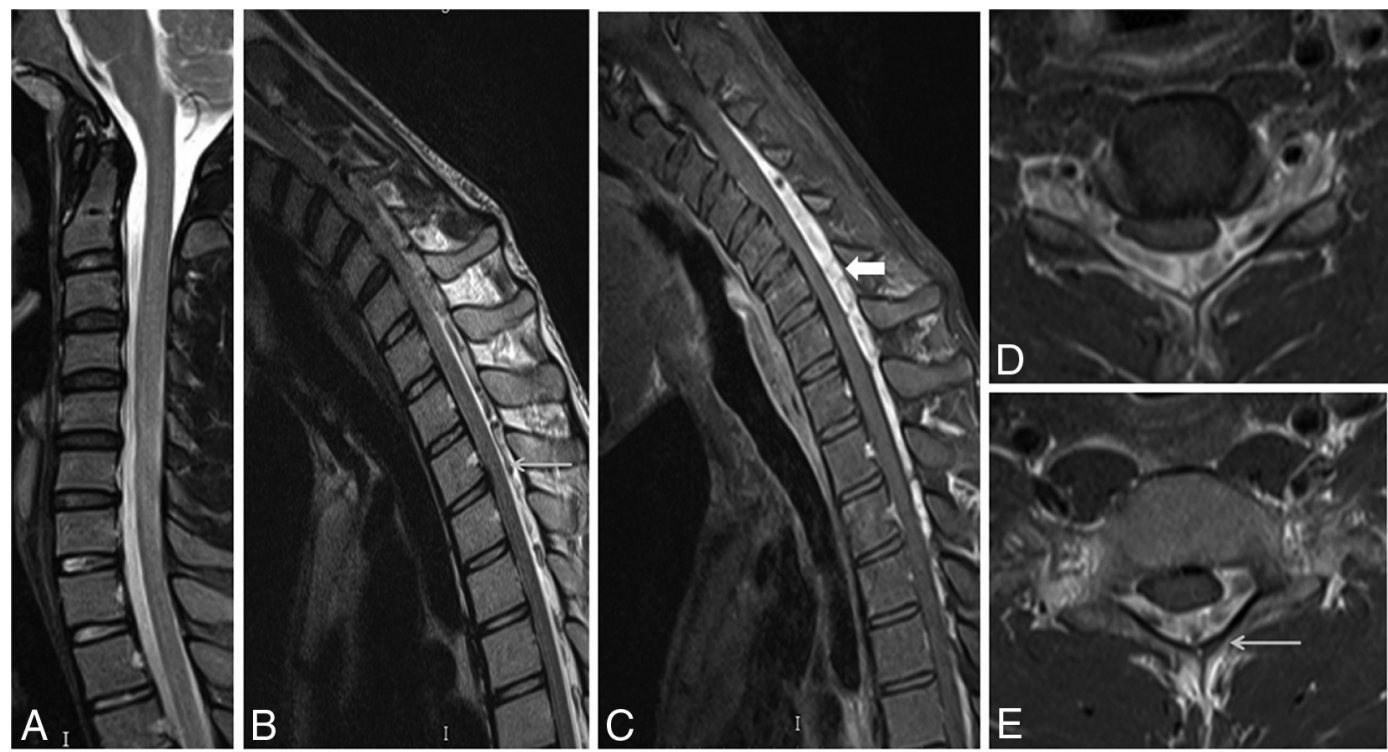

FIG 1. A 22-year-old man with wasting and weakness of the right hand and forearm muscles with cold paresis. Neutral position sagittal T2-weighted MR image (A) shows a normal appearance of the cervical cord. Flexion MR T2-weighted image (B) shows an enlarged posterior epidural space with multiple flow voids (arrow). Postgadolinium fat-suppressed sagittal T1-weighted flexion MR image (C) shows an enhancing epidural venous plexus extending from the C3 to T3 vertebral levels (block arrow). Axial postgadolinium T7 fat-suppressed images ( $D$ and $E$ ) show the enhancing posterior epidural venous plexus with flow voids within (arrow) and asymmetric flattening of the right hemicord.
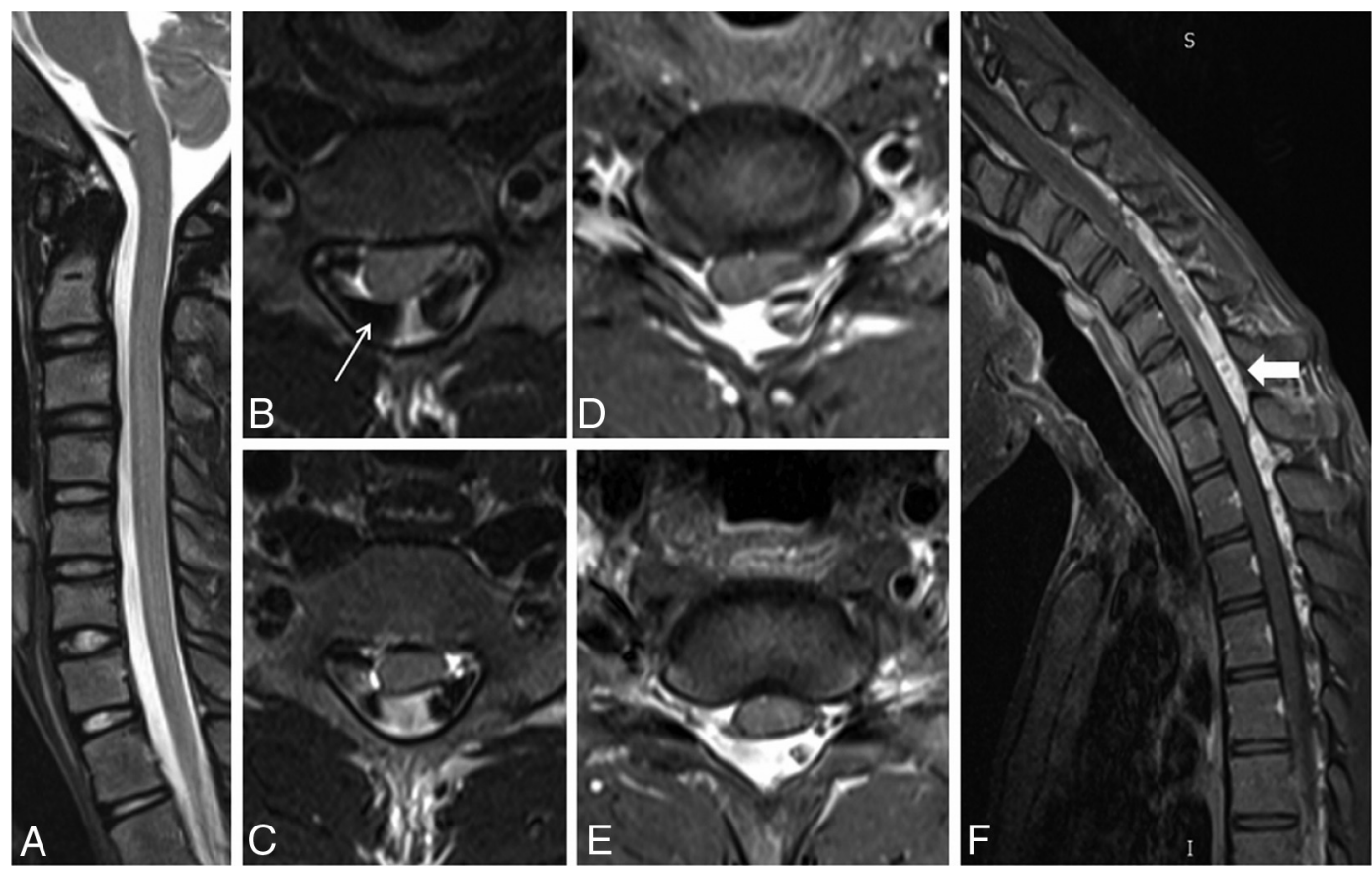

FIG 2. A 20-year-old male patient with weakness and wasting of the left hand muscles. Neutral position sagittal T2-weighted image (A) shows the normal appearance of the cervical cord. Axial T2-weighted flexion MR images ( $B$ and $C$ ) and postgadolinium T1 fat-suppressed images ( $D$ and E) show widening of the LDS with anterior displacement of the posterior dura and asymmetric cord atrophy, more on the left side, along with multiple flow voids within the posterior epidural space (arrow). Postgadolinium T1 fat-suppressed flexion MR sagittal image $(F)$ shows an enhancing posterior epidural venous plexus extending from the C4 to T4 vertebral level (block arrow).

The measurement of LDS at the maximum forward shifting of the posterior dural sac ranged from 3 to $9.8 \mathrm{~mm}$, with a mean diameter of $5.99 \pm 1.90 \mathrm{~mm}$ (Table 2). The mean LDS measured by radiologist 1 was $5.97 \pm 1.89 \mathrm{~mm}$ and by radiologist 2 , was $6.02 \pm 1.92 \mathrm{~mm}$. The significance between the 2 radiologists while measuring the LDS was an $F$ value of 0.043 and a $P$ value of .886 . The correlation between the 2 radiologists while measuring the
LDS had a Pearson correlation of 0.989 with a $P$ value of $<.001$. A scatterplot showing various LDS measurements by the 2 radiologists has been provided in Fig 4.

Posterior epidural flow voids were noted in 21 patients (46.7\%) (Fig 2). The enhancing crescentic posterior epidural space was noted only in the cervical region in 16 patients (35.6\%), while 29 patients $(64.4 \%)$ had involvement of the thoracic spinal 

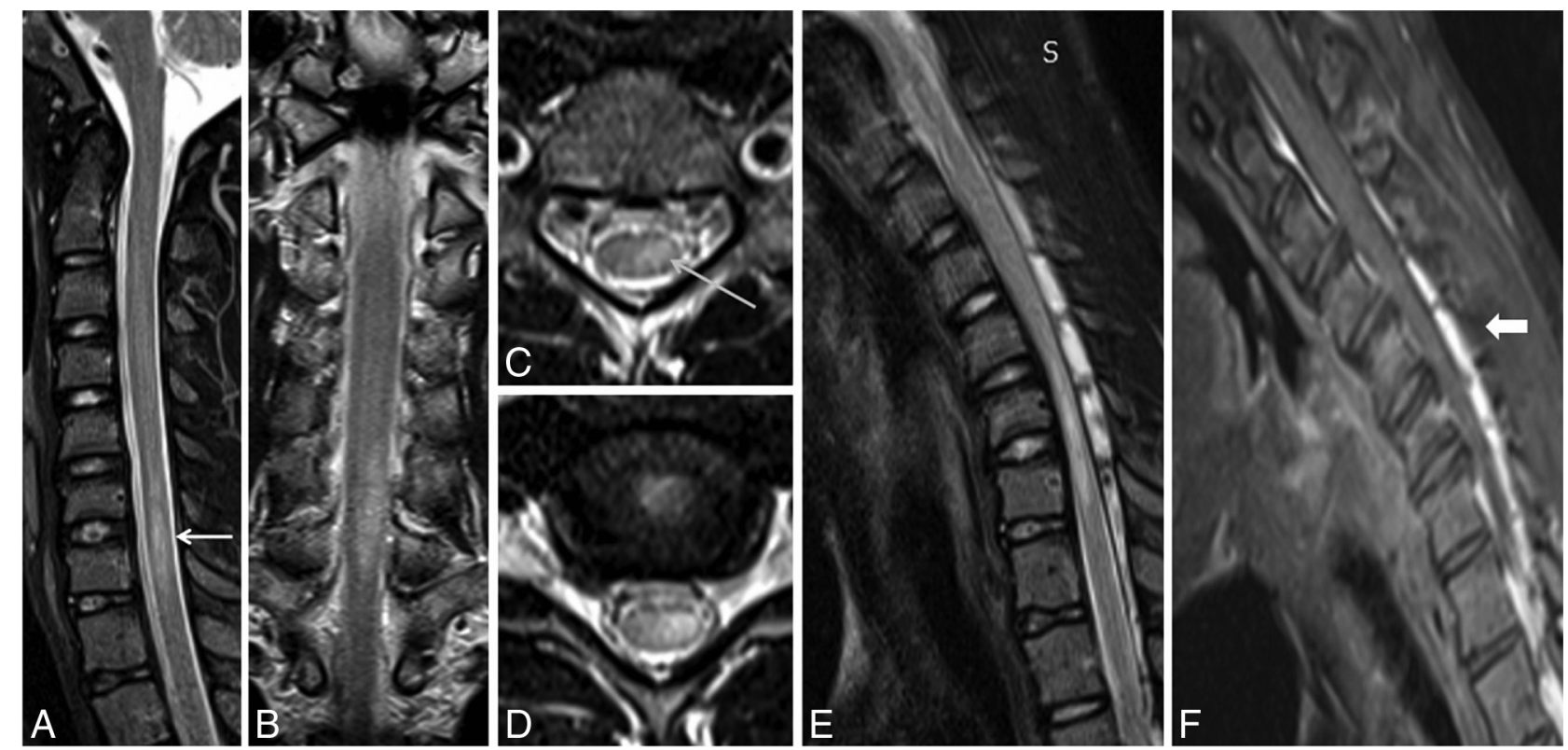

FIG 3. A 21-year-old man with asymmetric wasting of the bilateral hand muscles. Neutral MR T2-weighted sagittal and coronal ( $A$ and $B$ ) images show lower cervical cord atrophy with segmental hyperintensities in the cervical cord at the C6 and C7 vertebral levels (white arrow). Axial T2-weighted images ( $C$ and $D$ ) show asymmetric hyperintensities, more pronounced in the left half of the cervical cord (arrow). Flexion cervical MR STIR image (E) shows an enlarged posterior epidural space, which is seen as an enhancing posterior epidural venous plexus on the postgadolinium $T 1$ fat-suppressed sagittal image $(F)$ (block arrow).

Table 2: Summarized average results of measured parameters of 2 radiologists during neutral and flexion MRI in 45 patients with Hirayama disease

\begin{tabular}{lcccc}
\hline & Minimum & Maximum & Mean & \multicolumn{1}{c}{ SD } \\
\hline Distance of LDS & 3.00 & 9.80 & 5.9978 & 1.90424 \\
Spinal canal diameter in neutral MRI & 10.80 & 15.30 & 12.7756 & .99457 \\
Spinal canal diameter in flexion MRI & 10.90 & 15.50 & 12.9644 & 1.01604 \\
AP cord diameter at neutral MRI & 3.30 & 7.40 & 5.5378 & 1.00029 \\
TR cord diameter at neutral MRI & 7.50 & 14.40 & 12.1911 & 1.32593 \\
AP cord diameter at flexion MRI & 2.50 & 6.60 & 4.8089 & .96903 \\
TR cord diameter at flexion MRI & 9.20 & 16.20 & 14.1022 & 1.39569 \\
Ratio of LDS/spinal canal diameter in flexion MRI & 0.24 & 0.74 & 0.461 & 0.14 \\
Ratio of AP/TR diameter of cord in flexion MRI & 0.17 & 0.59 & 0.3455 & 0.08634 \\
Ratio of AP/TR diameter of cord in neutral MRI & 0.26 & 0.72 & 0.4587 & 0.09899 \\
Decrement of AP/TR diameter of cord during & 0.03 & 0.26 & 0.118 & 0.06 \\
flexion MRI & & & &
\end{tabular}

Note:-Measurements are in millimeters.

posterior epidural space along with the cervical spine (Fig 2). The average spinal canal diameter at the site of maximum thickness of the posterior epidural component during flexion was $12.96 \pm$ $1.01 \mathrm{~mm}$ and $12.77 \pm 0.99 \mathrm{~mm}$ during a neutral position. This finding indicates a slight increment in the AP dimension of the spinal canal during flexion MR imaging. In our study, the average AP diameter of the spinal cord during a neutral position of the neck was $5.54 \pm 1.0 \mathrm{~mm}$ and $4.82 \pm 0.97 \mathrm{~mm}$ during flexion. The average TR diameter of the spinal cord during neutral MR imaging was $12.2 \pm 1.33 \mathrm{~mm}$ and $14.1 \pm 1.4 \mathrm{~mm}$ during flexion MR imaging. The spinal cord was compressed and anteriorly displaced by the enhancing posterior epidural component during flexion MR imaging, leading to a decrease in the AP diameter and an increase in the TR diameter of the spinal cord at the maximum compression site. The ratio of maximum anteroposterior shifting of the posterior dural sac (ie, LDS)/maximum AP diameter of the spinal canal during flexion MR imaging had an average increment value of $0.46 \pm 0.14 \mathrm{~mm}$ (range, $0.24-0.74 \mathrm{~mm}$ ), indicating cord compression during flexion. The ratio of AP diameter of the cord/TR diameter of the cord during neutral MR imaging was $0.45 \pm 0.09 \mathrm{~mm}$ (range, 0.26-0.72 $\mathrm{mm})$. The ratio of AP diameter of the cord/TR diameter of the cord decreases during flexion because of cord compression and cord flattening. The decrement of the AP/TR cord ratio during flexion was $0.118 \pm 0.06 \mathrm{~mm}$ (Fig 5).

The frequency polygon in Fig 6 shows the LDS measurements of all the cases. There was statistical significance in the LDS measurement for the diagnosis of $\mathrm{HD}$ with a $P$ value of $<.001$. The $95 \%$ confidence interval was $5.42-6.57 \mathrm{~mm}$ with mean value of $5.99 \mathrm{~mm}$.

\section{DISCUSSION}

HD was initially recognized in Japan in 1959 by Hirayama et $\mathrm{al}^{1}$ and was initially reported under the name of juvenile muscular atrophy of unilateral upper extremity. It predominantly affects young adults and adolescents ranging from 15 to 25 years of age. However, it has also been reported in pediatric and old age groups. ${ }^{10,11}$ The initial symptoms of HD are slowly progressive hand weakness and fatigue, followed by cold paresis, tremors, and atrophy. Asymmetric distribution of symptoms and signs is characteristic, though bilaterally symmetric forms have also been reported recently. ${ }^{8,12} \mathrm{HD}$ may affect C5-C7 segmental myotomes more commonly in Western countries, whereas the C7-T1 segment is predominantly affected in Asian countries. ${ }^{4}$ Segment C7-T1 involvement was seen in all patients in our study.

Repeated or sustained flexion movements of the neck account for necrosis of the anterior horn cells of the lower cervical cord 


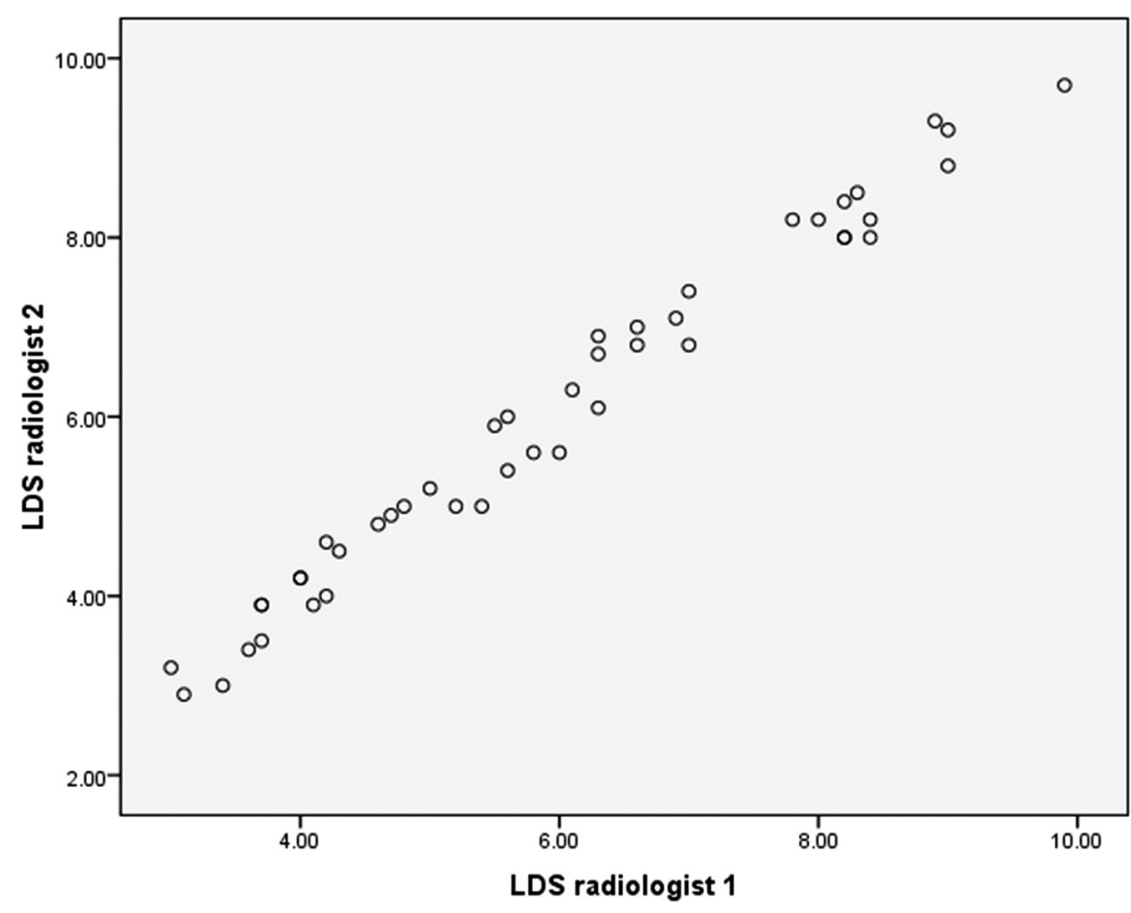

FIG 4. Scatterplot showing the various LDS measurements by the 2 radiologists.

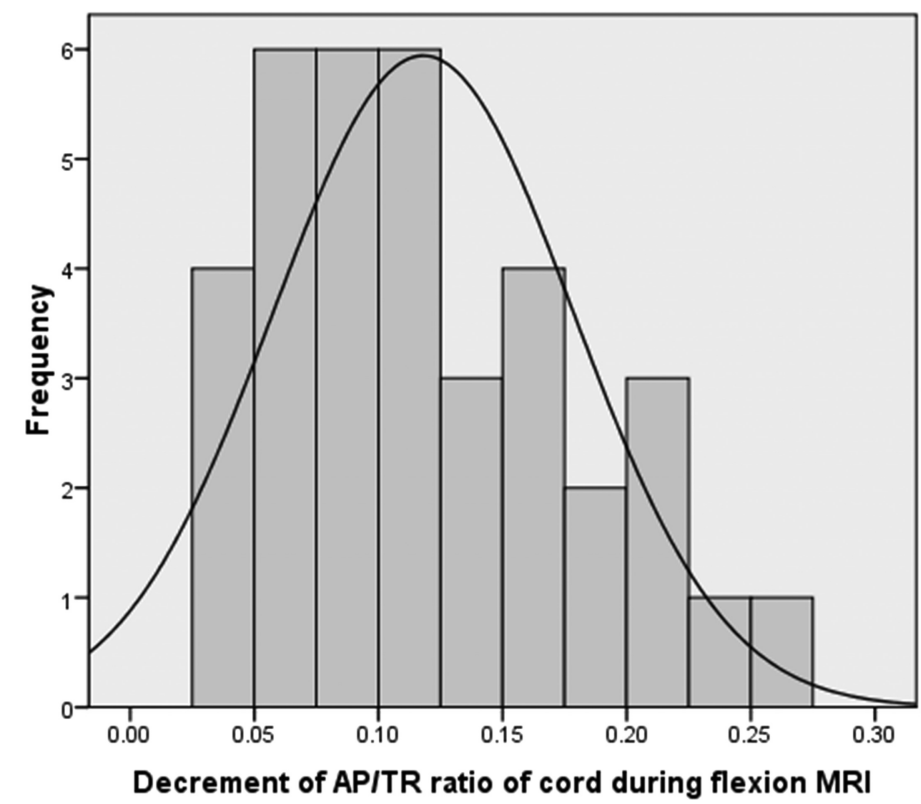

FIG 5. Histogram showing decrement in AP/TR cord diameter ratio during flexion cervical MR imaging in the 45 patients with Hirayama disease.

from chronic microcirculatory changes in the anterior spinal artery territory, which is thought to be the etiopathogenesis in HD. ${ }^{13}$ Another possible underlying cause might be an imbalance in growth between the individual vertebral column and spinal canal contents, which leads to abutment of the anterior spinal cord against the vertebral column and detachment of the posterior dura, leading to a widened LDS, ultimately causing microcirculatory disturbances and ischemic changes in the anterior spinal cord. ${ }^{14-17}$ Some authors also proposed atopy and elevated serum immunoglobulin E levels as participating factors. ${ }^{18}$ Tanaka et al ${ }^{19}$ observed the intrathecal upregulation of proinflammatory T-helper-1 cytokines/ chemokines, such as interferon- $\gamma$ and macrophage inflammatory proteins- $1 \beta$ chemokine, in the CSF of patients with $\mathrm{HD}$, indicating the possible involvement of intrathecal immunologic processes in this condition. In 2010, Ciceri et al ${ }^{20}$ proposed that venous congestion in flexion might play an additional role in determining spinal cord ischemic changes. Venous engorgement is thought to be secondary to an impaired venous drainage toward the jugular veins during neck flexion and an increased flow to the posterior internal vertebral venous plexus resulting from the negative pressure in the posterior epidural space because of anterior shifting of the dura.

Imaging plays a very important role in the diagnosis of HD. Plain radiographs may only show loss of cervical lordosis, which is a very nonspecific finding. MR imaging is the best technique in the diagnosis of this entity. Conventional neutral position MR imaging may show an atrophied lower cervical cord and asymmetric cervical cord flattening with or without abnormal T2-weighted hyperintensities in the cervical cord, especially the anterior horn cells. More important is MR imaging in neck flexion, which reveals classic findings of posterior dural detachment with forward shifting of the posterior dural sac and loss of attachment between the posterior dural sac and the subjacent lamina, leading to a widened LDS. Postgadolinium flexion MR images demonstrate moderate-tointense enhancement in the engorged posterior epidural venous plexus, forming a crescent-shaped epidural mass, which exerts a compression effect over the cord with or without flow voids. ${ }^{14,21}$ Gupta et $\mathrm{al}^{22}$ proposed the use of 3D-CISS for better visualization of the epidural flow voids on MR imaging. Although most existing literature suggests the need for flexion MR imaging in the diagnosis of HD, Lehman et al ${ }^{23}$ in 2013 reported that neutral MR imaging itself was highly specific with moderately high sensitivity. They also reported that the findings of $\mathrm{HD}$, though subtle, are often present in neutral scans, though the diagnostic confidence may be less. Chen et $\mathrm{al}^{15}$ in 2004 proposed "loss of attachment" from the posterior dural sac and subjacent lamina as the most valuable finding in the diagnosis of HD, reporting a prevalence of $93 \%$ in their study group. 


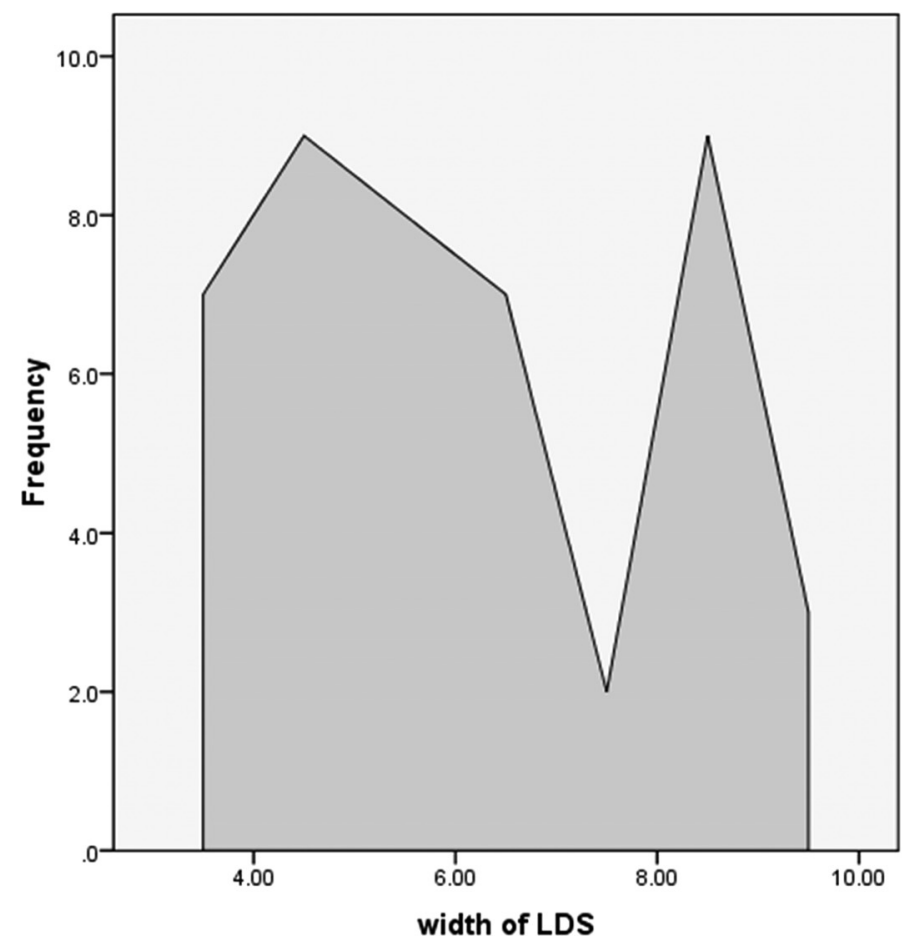

FIG 6. Frequency polygon showing the laminodural space measurements (in millimeters) during flexion cervical MR imaging in the 45 patients with HD.

However, Lai et $\mathrm{al}^{9}$ observed that forward shifting of the posterior dural sac was also seen in healthy subjects in up to $46 \%$ of patients, but without spinal cord compression. They further noted that the distance of such a forward shift was mild, ranging from 1.0 to $4.2 \mathrm{~mm}$ with a mean of $1 \mathrm{~mm}$, compared with those with $\mathrm{HD}$ in whom it ranged from 6.1 to $7.8 \mathrm{~mm}$, with a mean of $6.7 \mathrm{~mm}$. They studied the increment in the ratio of the AP diameter of forward displacement of the posterior dural wall/AP diameter of the spinal canal and the decrement in the ratio of the AP diameter of the spinal cord/TR diameter of the spinal cord. They concluded that the ratio of LDS at the site of maximum forward shift to the spinal canal diameter should be increased in HD with a decreased ratio of the AP/TR diameter of the spinal cord in flexion compared with the neutral position. These ratios do not significantly change in healthy subjects. ${ }^{9}$ However, the major limitation of their study was the small sample size of 3 patients. We applied the findings to a larger study group. In our study of 45 patients with $\mathrm{HD}$, the ratio of maximum LDS/maximum AP diameter of the spinal canal during flexion MR imaging had an average increment value of $0.46 \pm 0.14 \mathrm{~mm}$. The ratio of the AP diameter of the cord/TR diameter of the cord during neutral MR imaging was $0.45 \pm 0.09 \mathrm{~mm}$, which decreased during flexion MR imaging because of cord compression and cord flattening. The mean decrement of the AP/TR cord ratio during flexion MR imaging was $0.118 \pm 0.06 \mathrm{~mm}$.

We acknowledge the limitations in our study. We did not have a control group to compare LDS distance and decide the exact cutoff to label as HD. A uniform angle of neck flexion could not be achieved in all patients due to subject bias. In the future, further case-control studies are necessary to obtain the mean LDS in healthy individuals.

HD has a self-limiting course, and treatment is usually conserva- tive. The management includes reducing repeat trauma to the cervical cord by avoiding repeat neck flexion by the use of a soft cervical collar during the progressive stage of the disease process, which is shown to arrest the disease progression. ${ }^{24}$ Even surgical interventions such as cervical decompression and fusion with or without duraplasty or cervical duraplasty with tenting sutures via laminoplasty without cervical fusion may be advocated in selected patients. ${ }^{25,26}$ Hence, early recognition of $\mathrm{HD}$ is necessary because the patient can be advised to avoid or limit neck flexion movements, which helps in arresting further progression of this disease. So, a high index of clinical suspicion is necessary to diagnose this entity because neutral MR imaging may fail to diagnose it.

\section{CONCLUSIONS}

High clinical suspicion of HD is necessary in young patients with insidious onset of weakness of the hand and forearm muscles with muscle flaccidity. Flexion MR imaging sequences must be obtained to look for LDS widening and anterior displacement of the posterior dura mater because it can be missed on conventional neutral position MR images.

The ratio of the LDS at maximum forward shift to the spinal canal diameter is increased in HD with decrement of the AP/TR diameter of the spinal cord during flexion MR imaging. The forward shifting of the posterior cervical dural sac on flexion MR imaging can also be seen in healthy subjects, but associated cord compression, if present, is helpful to clinch the diagnosis.

\section{ACKNOWLEDGMENTS}

We are thankful to Dr V. Preethish Kumar for his assistance in editing the manuscript.

\section{REFERENCES}

1. Hirayama K, Toyokura Y, Tsubaki T. Juvenile muscular atrophy unilateral upper extremity a new clinical entity. PsychiatrNeurol Jpn 1959;61:2190-97

2. Biondi A, Dormont D, Weitzner I Jr, et al. MR imaging of the cervical cord in juvenile amyotrophy of distal upper extremity. AJNR Am J Neuroradiol 1989;10:263-68 Medline

3. Gourie-Devi M, Suresh TG, Shankar SK. Monomelic amyotrophy. Arch Neurol 1984;41:388-94 CrossRef Medline

4. de Carvalho M, Swash M. Monomelic neurogenic syndromes: a prospective study. J Neurol Sci 2007;263:26-34 CrossRef Medline

5. Di Muzio A, Delli Pizzi C, Lugaresi A, et al. Benign monomelic amyotrophy of lower limb: a rare entity with a characteristic muscular CT. J Neurol Sci 1994;126:153-61 CrossRef Medline

6. Guo XM, Qin XY, Huang C. Neuroelectrophysiological characteristics of Hirayama disease: report of $\mathbf{1 4}$ cases. Chin Med J (Engl) 2012;125:2440-43 Medline

7. Nalini A, Gourie-Devi M, Thennarasu K, et al. Monomelic amyotrophy: clinical profile and natural history of 279 cases seen 
over 35 years (1976-2010). Amyotroph Lateral Scler Frontotemporal Degener 2014;15:457-65 CrossRef Medline

8. Pradhan S. Bilaterally symmetric form of Hirayama disease. Neurology 2009;72:2083-89 CrossRef Medline

9. Lai V, Wong YC, Poon WL, et al. Forward shifting of posterior dural sac during flexion cervical magnetic resonance imaging in Hirayama disease: an initial study on normal subjects compared to patients with Hirayama disease. Eur J Radiol 2011;80:724-28 CrossRef Medline

10. Patel DR, Knepper L, Jones HR Jr. Late-onset monomelic amyotrophy in a Caucasian woman. Muscle Nerve 2008;37:115-19 CrossRef Medline

11. Yilmaz O, Alemdaroğlu I, Karaduman A, et al. Benign monomelic amyotrophy in a 7-year-old girl with proximal upper limb involvement: case report. Turk J Pediatr 2011;53:471-76 Medline

12. Preethish-Kumar V, Nalini A, Singh RJ, et al. Distal bimelic amyotrophy (DBMA): phenotypically distinct but identical on cervical spine MR imaging with brachial monomelic amyotrophy/Hirayama disease. Amyotroph Lateral Scler Frontotemporal Degener 2015;16:338-44 CrossRef Medline

13. Raval M, Kumari R, Dung AA, et al. MRI findings in Hirayama disease. Indian J Radiol Imaging 2010;20:245-49 CrossRef Medline

14. Abraham A, Gotkine M, Drory VE, et al. Effect of neck flexion on somatosensory and motor evoked potentials in Hirayama disease. J Neurol Sci 2013;334:102-05 CrossRef Medline

15. Chen CJ, Hsu HL, Tseng YC, et al. Hirayama flexion myelopathy: neutral-position MR imaging findings-importance of loss of attachment. Radiology 2004;231:39-44 CrossRef Medline

16. Foster E, Tsang BK, Kam A, et al. Mechanisms of upper limb amyotrophy in spinal disorders. J Clin Neurosci 2014;21:1209-14 CrossRef Medline

17. Gotkine M, Abraham A, Drory VE, et al. Dynamic MRI testing of the cervical spine has prognostic significance in patients with progressive upper-limb weakness and atrophy. J Neurol Sci 2014;345: 168-71 CrossRef Medline

18. Vitale V, Caranci F, Pisciotta C, et al. Hirayama's disease: an Italian single center experience and review of the literature. Quant Imaging Med Surg 2016;6:364-73 CrossRef Medline

19. Tanaka M, Ishizu T, Ochi H, et al. Intrathecal upregulation of IFNgamma and MIP-1beta in juvenile muscular atrophy of the distal upper extremity. J Neurol Sci 2008;275:74-77 CrossRef Medline

20. Ciceri EF, Chiapparini L, Erbetta A, et al. Angiographically proven cervical venous engorgement: a possible concurrent cause in the pathophysiology of Hirayama's myelopathy. Neurol Sci 2010;31: 845-48 CrossRef Medline

21. Gandhi D, Goyal M, Bourque PR, et al. Case 68: Hirayama disease. Radiology 2004;230:692-96 CrossRef Medline

22. Gupta K, Sood S, Modi J, et al. Imaging in Hirayama disease. J Neurosci Rural Pract 2016;7:164-67 CrossRef Medline

23. Lehman VT, Luetmer PH, Sorenson EJ, et al. Cervical spine MR imaging findings of patients with Hirayama disease in North America: a multisite study. AJNR Am J Neuroradiol 2013;34:451-56 CrossRef Medline

24. Tokumaru Y, Hirayama K. Cervical collar therapy for juvenile muscular atrophy of distal upper extremity (Hirayama disease): results from 38 cases [in Japanese]. Rinsho Shinkeigaku 2001;41:173-78 Medline

25. Chiba S, Yonekura K, Nonaka M, et al. Advanced Hirayama disease with successful improvement of activities of daily living by operative reconstruction. Intern Med 2004;43:79-81 CrossRef Medline

26. Ito $\mathrm{H}$, Takai $\mathrm{K}$, Taniguchi $\mathrm{M}$. Cervical duraplasty with tenting sutures via laminoplasty for cervical flexion myelopathy in patients with Hirayama disease: successful decompression of a "tight dural canal in flexion" without spinal fusion. J Neurosurg Spine 2014;21: 743-52 CrossRef Medline 